\title{
Optical Coherence Tomography-Derived Anatomical Criteria for Functionally Significant Coronary Stenosis Assessed by Fractional Flow Reserve
}

Yasutsugu Shiono, MD; Hironori Kitabata, MD, PhD; Takashi Kubo, MD, PhD;

Tomizou Masuno, MD; Shingo Ohta, MD; Yuichi Ozaki, MD; Hiromichi Sougawa, MD;

Makoto Orii, MD; Kunihiro Shimamura, MD; Kohei Ishibashi, MD; Kenichi Komukai, MD;

Takashi Yamano, MD; Takashi Tanimoto, MD, PhD; Yasushi Ino, MD, PhD;

Tomoyuki Yamaguchi, MD; Kumiko Hirata, MD, PhD; Masato Mizukoshi, MD, PhD;

Toshio Imanishi, MD, PhD; Takashi Akasaka, MD, PhD

\begin{abstract}
Background: For the identification of functionally significant coronary artery disease, there have not been any dedicated optical coherence tomography (OCT) studies reported previously, although OCT can clearly detect coronary vessel lumina at higher resolution than intravascular ultrasound (IVUS).

Methods and Results: OCT and fractional flow reserve (FFR) measurements were performed in 62 intermediate coronary lesions in 59 patients. FFR was calculated as the ratio of distal coronary pressure divided by proximal coronary pressure during maximal hyperemia. FFR $<0.75$ was used as the threshold for diagnosing functionally significant stenosis. Minimal lumen area (MLA), minimal lumen diameter (MLD) and percent lumen area stenosis were measured by OCT. FFR values correlated significantly with OCT-derived MLA ( $r=0.75, P<0.01), M L D(r=0.76$, $\mathrm{P}<0.01)$ and percent lumen area stenosis $(r=-0.77, P<0.01)$. Receiver-operating characteristic curve suggested an OCT-derived MLA $<1.91 \mathrm{~mm}^{2}$ (sensitivity $93.5 \%$, specificity $77.4 \%$ ), MLD $<1.35 \mathrm{~mm}$ (sensitivity $90.3 \%$, specificity $80.6 \%$ ) and percent lumen area stenosis $>70.0 \%$ (sensitivity $96.8 \%$, specificity $83.9 \%$ ) as the best cutoff values for a FFR $<0.75$.
\end{abstract}

Conclusions: Anatomical measurements of coronary stenosis obtained by OCT show significant correlation with FFR. OCT has the potential to predict functionally significant stenosis, although the present OCT-derived parameters were smaller than those reported in previous IVUS studies. (Circ $J$ 2012; 76: 2218-2225)

Key Words: Fractional flow reserve; Intermediate coronary stenosis; Optical coherence tomography

$\mathbf{I}$ $\mathrm{n}$ patients with coronary artery disease, the presence of myocardial ischemia is an important risk factor for adverse clinical outcome. ${ }^{1}$ Although coronary angiography (CAG) is the standard method for evaluating coronary lesions, ${ }^{2}$ visual estimation of lesion severity on $\mathrm{CAG}$, even with quantitative CAG, is not guaranteed to accurately predict the presence of myocardial ischemia. Noninvasive stress tests before diagnostic CAG are often not performed, and the results are sometimes inconclusive. ${ }^{3}$ At present, several intracoronary modalities can be used, such as pressure wire, intravascular ultrasound (IVUS), and optical coherence tomography (OCT), to evaluate coronary lesions accurately. Fractional flow reserve (FFR) measured by pressure wire is an established index for invasively evaluating the functional significance of coronary stenosis. ${ }^{4}$ The presence of inducible myocardial ischemia determines the potential benefit of the revascularization procedure. ${ }^{5,6}$ FFR-guided percutaneous coronary intervention (PCI) is associated with reduced major adverse cardiac events. ${ }^{7-9}$

\section{Editorial p 2092}

Previous studies have demonstrated that the minimal lumen area (MLA) measured by IVUS correlates with FFR and that a MLA $<3.0 \mathrm{~mm}^{2}$ or $<4.0 \mathrm{~mm}^{2}$ is a useful threshold for predicting functionally significant stenosis with a FFR $<0.75 . .^{10,11}$

Recently, we used OCT, which has a 10-fold higher resolution than IVUS, to investigate coronary artery disease. ${ }^{12,13}$ With its excellent resolution, OCT provides not only detailed mor-

Received February 14, 2012; revised manuscript received May 1, 2012; accepted May 18, 2012; released online June 21, 2012 Time for primary review: 21 days

Department of Cardiovascular Medicine, Wakayama Medical University, Wakayama, Japan

Mailing address: Takashi Kubo, MD, PhD, Department of Cardiovascular Medicine, Wakayama Medical University, 811-1 Kimiidera, Wakayama 641-8509, Japan. E-mail: takakubo@ wakayama-med.ac.jp

ISSN-1346-9843 doi:10.1253/circj.CJ-12-0195

All rights are reserved to the Japanese Circulation Society. For permissions, please e-mail: cj@j-circ.or.jp 
phological information, but also clear anatomical quantitative information about coronary lesions. Furthermore, OCT is useful for risk stratification of PCI patients, including predicting the post-procedure no-reflow phenomenon. ${ }^{14}$ However, the relationship between anatomical quantitative measurement by OCT and FFR has not been investigated. The aims of this study, therefore, were to (1) investigate the relationship between quantitative OCT parameters and FFR, and (2) assess whether quantitative OCT measurements can predict the functional severity of coronary lesions evaluated by FFR.

\section{Methods}

\section{Study Population}

Between January 2007 and August 2011, 59 patients with 62 coronary lesions who had undergone both OCT and physiological assessment by pressure wire at diagnostic catheterization or before PCI were retrospectively examined. All patients were interviewed about their medical history and their cardiac function was evaluated by echocardiography (Simpson's method) before cardiac catheterization. They all had at least 1 target vessel with stenosis ( $>30 \%$ diameter stenosis by visual estimation) including de novo or in-stent restenosis lesions. We excluded multiple stenoses in the same epicardial coronary artery (tandem lesion, $>2$ stenoses in the same coronary artery by visual estimation), bypass graft disease, left main coronary artery disease, side-branch lesions, presence of collateral vessels, and thrombi-containing lesions. Written informed consent was given by all patients participating in the study.

\section{Cardiac Catheterization}

After intravenous administration of $8,000 \mathrm{IU}$ heparin, a 5 or 6 Fr catheter without side holes was seated in the coronary ostium via the transradial or transfemoral artery approach. After intracoronary administration of $2.0 \mathrm{mg}$ of isosorbide dinitrate through a catheter, CAG was performed in multiple projections.

\section{Angiographic Analysis}

Quantitative angiographic analysis (QCA) was performed by standard techniques with an automated edge-detection algorithm (CASS-5, Pie Medical, Maastricht, the Netherlands) by an independent investigator (K.K.) who was unaware of the clinical presentations, results of FFR measurements, and OCT findings. Image calibration was performed with a contrast-filled catheter. The external diameter of the catheter was used as the calibration standard. Coronary end-diastolic frames from matched views obtained by angiography were analyzed with an automated contour detection system. Reference lumen diameter, minimal lumen diameter (MLD), and lesion length were measured. Percent diameter stenosis was calculated as the reference lumen diameter minus the MLD divided by the reference lumen diameter.

\section{FFR Measurement}

To measure distal coronary pressure, a 0.014-inch pressure guidewire (Pressure wire 5 or Certus, St. Jude Medical, Uppsala, St. Paul, MN, USA) was advanced across the stenosis, and the pressure sensor was positioned as distal to the coronary stenosis as possible. Proximal coronary pressure was recorded by the guiding catheter. Maximal hyperemia was induced by continuous adenosine triphosphate (ATP: $150 \mu \mathrm{g} \cdot \mathrm{kg}^{-1} \cdot \mathrm{min}^{-1}$ ) infusion via the femoral vein. In the case of an intermediate FFR measurement of $0.75-0.80$ or uncertain maximal hyper- emia, the dose of ATP was increased to $180 \mu \mathrm{g} \cdot \mathrm{kg}^{-1} \cdot \mathrm{min}^{-1}$. FFR is calculated as the mean distal coronary pressure (measured with the pressure guidewire) divided by the mean aortic pressure (measured simultaneously via a 5 or $6 \mathrm{Fr}$ catheter) during maximal hyperemia. Based on the results of earlier studies, ${ }^{4,15}$ the stenosis was considered functionally significant with FFR $<0.75$. At the end of the FFR measurement, the pressure guidewire was manually pulled back slowly from the most distal to the most proximal part of the artery during induced steady-state maximal hyperemia in all patients. When the pressure sensor was pulled back into the guiding catheter, both pressures were checked to exclude transducer drift. If there was a difference $>5 \mathrm{mmHg}$ between the pressure of the guiding catheter and the pressure of the guidewire, the FFR values were corrected by manual recalculation.

\section{OCT Imaging Acquisition}

We used a time-domain OCT system (TD-OCT, M2, LightLab Imaging, Inc, Westford, MA, USA). ${ }^{12}$ For the TD-OCT procedure, the z-offset was adjusted before acquisition of every image while holding the image wire between 2 fingers and advancing it distal to the target stenosis. All OCT procedures used the conventional occlusion technique. The targeted coronary artery was occluded using an occlusion balloon catheter (OBC) at the proximal site of the targeted stenosis followed by flushing with lactate Ringer's or low-molecular-weight dextran from the tip of the $\mathrm{OBC}$ at a rate of $0.5 \mathrm{ml} / \mathrm{s}$. The refraction index was adjusted to each flushing solution used. All OCT images were obtained using the automatic pullback function at a rate of $1.0 \mathrm{~mm} / \mathrm{s}$. The frame rate of image acquisition was $15.6 \mathrm{frames} / \mathrm{s}$.

\section{OCT Quantitative Analysis}

Analysis of OCT images was performed with proprietary LightLab software for offline analysis (LightLab Imaging) by an independent investigator (K.I.) who was unaware of the QCA data and the results of FFR measurements. Data were imported to the workstation in the LightLab database format. The lumen contour was obtained using an automated detection algorithm available in LightLab, and additional manual corrections were performed if necessary. MLA was defined as the smallest lumen area along the length of the target lesion, and MLD was defined as the smallest lumen diameter from 1 intimal leading edge to another along any line passing through the center of the lumen. The reference lumen area was defined as the site with the largest lumen either proximal or distal to the stenosis within the same segment (within $10 \mathrm{~mm}$ of the stenosis with no major intervening branches), and the mean reference lumen area was calculated as the distal plus proximal reference lumen areas divided by 2 . Percent luminal area stenosis was defined as the relative decrease in luminal area of the target lesion when compared with the reference lumen area in the same vessel segment. Percent luminal area stenosis was calculated as the mean reference lumen area minus the MLA divided by the mean reference lumen diameter. Lesion length was defined as the length between the proximal and distal references measured by the duration of the pullback and the pullback speed of the imaging catheter.

\section{Statistical Analysis}

Statistical analysis was performed using SPSS (version 11.0, SPSS Inc, Chicago, IL, USA). Values are expressed as mean \pm standard deviation for continuous variables or as number and percentage for categorical variables. The relationship and variability between FFR and quantitative OCT parameters in the 


\begin{tabular}{|lc|}
\hline Table 1. Patients' Characteristics ( $\mathbf{n = 5 9 )}$ & \\
Men, $\mathrm{n}(\%)$ & $49(79.0)$ \\
Age, years & $66.9 \pm 10.9$ \\
Body height, $\mathrm{cm}$ & $164.1 \pm 7.7$ \\
Body weight, $\mathrm{kg}$ & $66.3 \pm 11.4$ \\
Body mass index & $24.5 \pm 3.1$ \\
Ejection fraction, \% & $58.8 \pm 7.3$ \\
Dyslipidemia, $\mathrm{n}(\%)$ & $45(76.3)$ \\
Hypertension, $\mathrm{n}(\%)$ & $51(86.4)$ \\
Diabetes mellitus, $\mathrm{n}(\%)$ & $34(57.6)$ \\
Hemodialysis, $\mathrm{n}(\%)$ & $2(3.4)$ \\
Current smoking, $\mathrm{n}(\%)$ & $34(57.6)$ \\
Familial history, $\mathrm{n}(\%)$ & $11(18.6)$ \\
Previous myocardial infarction, $\mathrm{n}(\%)$ & $22(37.2)$ \\
\hline
\end{tabular}

Values are presented as mean \pm SD or $n(\%)$.

\begin{tabular}{|c|c|}
\hline \multicolumn{2}{|l|}{ Lesion location } \\
\hline Left anterior descending, $\mathrm{n}(\%)$ & $37(59.7)$ \\
\hline Right coronary artery, n (\%) & $16(25.8)$ \\
\hline Circumflex artery, n (\%) & $9(14.5)$ \\
\hline \multicolumn{2}{|l|}{ QCA parameters } \\
\hline Reference diameter, mm & $3.17 \pm 0.51$ \\
\hline$\%$ Diameter stenosis, \% & $58.2 \pm 17.0$ \\
\hline Minimum lumen diameter, mm & $1.30 \pm 0.56$ \\
\hline Lesion length, $\mathrm{mm}$ & $20.2 \pm 12.2$ \\
\hline \multicolumn{2}{|l|}{ Physiological parameter } \\
\hline Fractional flow reserve & $0.72 \pm 0.14$ \\
\hline
\end{tabular}

Values are presented as mean \pm SD or $n(\%)$.

$\mathrm{QCA}$, quantitative coronary angiography.

\begin{tabular}{|lr|}
\hline Table 3. OCT Parameters $\mathbf{n}=62)$ & \\
\hline Minimum lumen area, $\mathrm{mm}^{2}$ & $1.90 \pm 0.94$ \\
Minimum lumen diameter, $\mathrm{mm}$ & $1.33 \pm 0.38$ \\
Proximal reference lumen cross-sectional area, & $6.79 \pm 1.74$ \\
$\mathrm{~mm}^{2}$ & \\
Distal reference lumen cross-sectional area, $\mathrm{mm}^{2}$ & $5.82 \pm 1.76$ \\
Mean reference lumen cross-sectional area, $\mathrm{mm}^{2}$ & $6.30 \pm 1.72$ \\
Lumen area stenosis, \% & $68.9 \pm 15.4$ \\
Lesion length, $\mathrm{mm}$ & $18.74 \pm 9.71$ \\
\hline
\end{tabular}

Values are presented as mean \pm SD.

OCT, optical coherence tomography.

scattergrams were analyzed using Pearson's correlation coefficient test. A receiver-operating characteristic curve was used to determine the best cutoff values of quantitative OCT parameters to predict an FFR $<0.75$. The best cutoff value was defined as the value with the highest sum of sensitivity and specificity. $\mathrm{P}<0.05$ was considered statistically significant.

\section{Results}

\section{Patients' Characteristics}

The patients' characteristics are summarized in Table 1. A total of 34 patients $(57.6 \%)$ had diabetes mellitus and 51 $(86.4 \%)$ had hypertension. The average ejection fraction was $58.8 \pm 7.3 \%$.

\section{Lesion Characteristics}

The study vessels and lesion locations are shown in Figure 1. The left anterior descending artery (LAD) was the most common studied vessel (37 lesions, 62.7\%). Offline QCA was per-

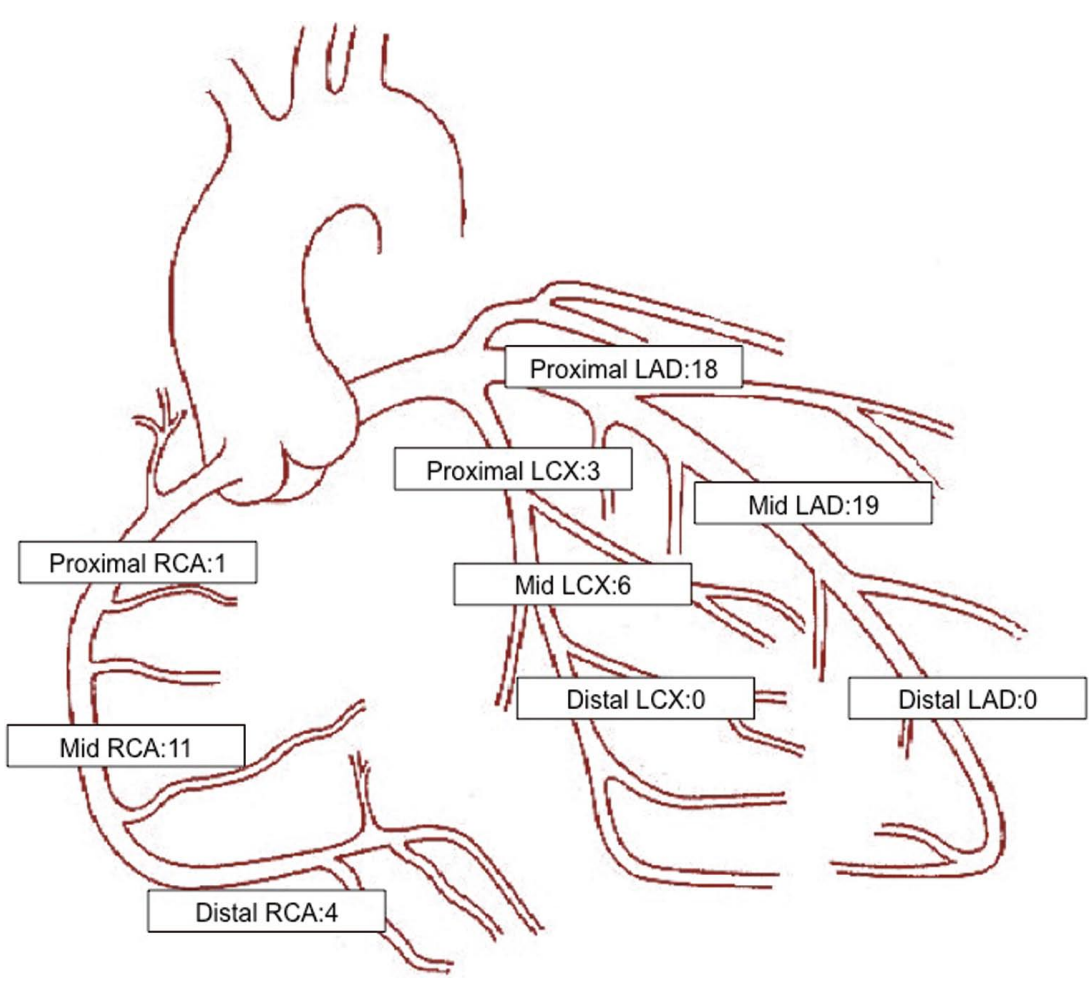

Figure 1. Studied vessels and lesion location. Lesions $(n=62)$ included 37 in the left anterior descending artery (LAD), 9 in the left circumflex coronary artery (LCX) and 16 in the right coronary artery (RCA). 

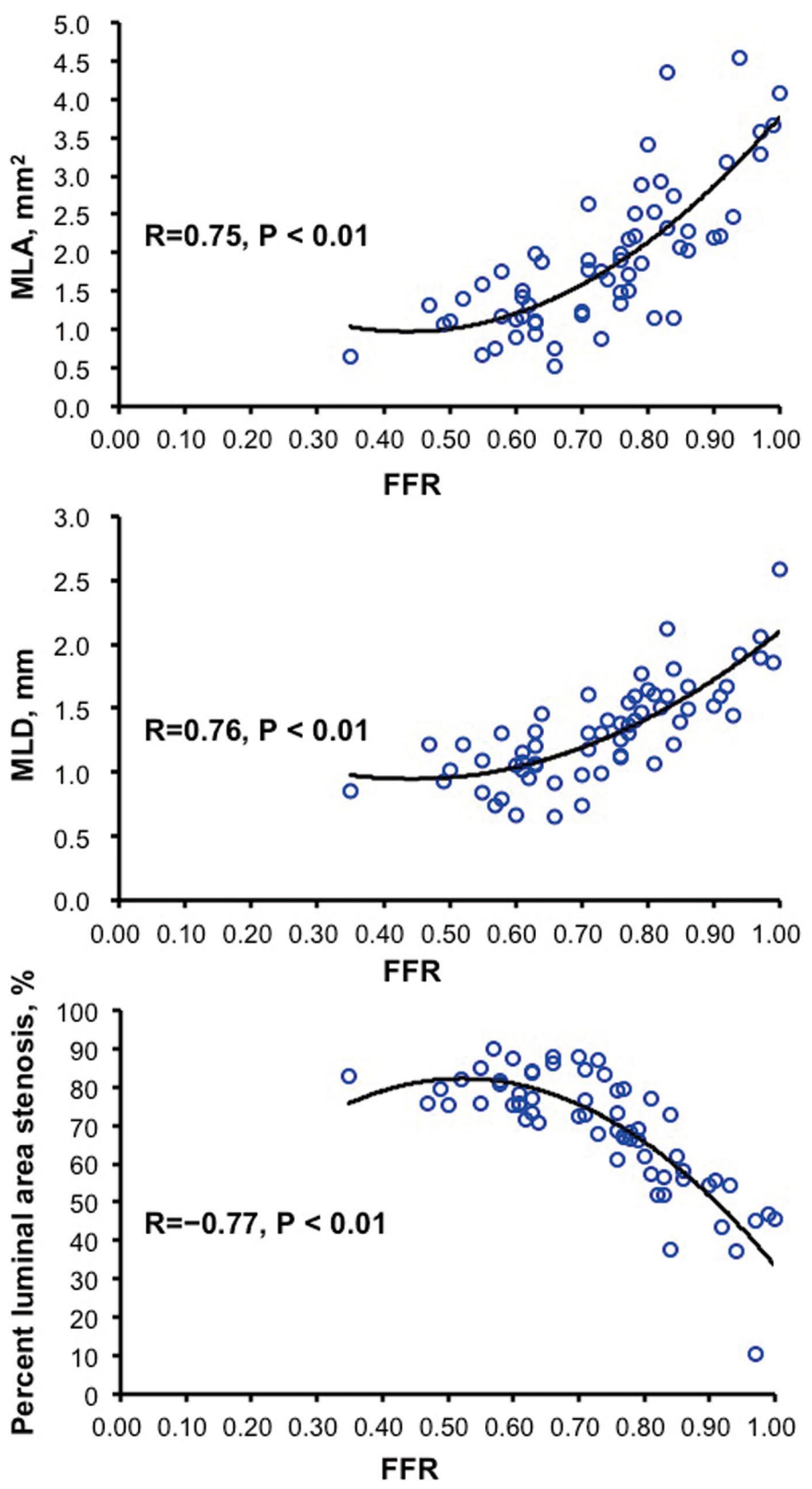

Figure 2. Relationship between fractional flow reserve (FFR) and optical coherence tomography (OCT) parameters. FFR correlated significantly with OCT-derived MLA ( $r=0.75$, $P<0.01)$, MLD $(r=0.76, P<0.01)$ and percent luminal area stenosis $(r=-0.77, P<0.01)$. MLA, minimal lumen area; MLD, minimal lumen diameter.

formed for all study lesions (Table 2). The average reference vessel diameter, MLD, diameter stenosis and lesion length were $3.17 \pm 0.51 \mathrm{~mm}, 1.30 \pm 0.56 \mathrm{~mm}, 58.2 \pm 17.0 \%$, and $20.2 \pm 12.2 \mathrm{~mm}$, respectively.

\section{Quantitative OCT Measurement}

All OCT image acquisitions were successfully performed without serious complications. The results of quantitative OCT measurements are summarized in Table 3. Mean MLA, reference lumen area, percent lumen area stenosis and lesion length were $1.90 \pm 0.94 \mathrm{~mm}^{2}$ (range, $0.52-4.55 \mathrm{~mm}^{2}$ ), $6.30 \pm 1.72 \mathrm{~mm}^{2}$ (range, 3.74-11.40 $\mathrm{mm}^{2}$ ), 68.9 $115.4 \%$ (range, 10.4-90.0\%) and $18.74 \pm 9.71 \mathrm{~mm}$ (range, $5.3-39.2 \mathrm{~mm}$ ), respectively.

\section{FFR Measurement}

Coronary pressure was successfully measured, and FFR was calculated in all cases. There were 4 cases $(6.5 \%)$ of pressure drift and the FFR values were corrected by manual recalculation. In 12 cases $(20.3 \%)$ of an intermediate FFR value (0.750.80 ) or uncertain maximal hyperemia, we increased the dose 


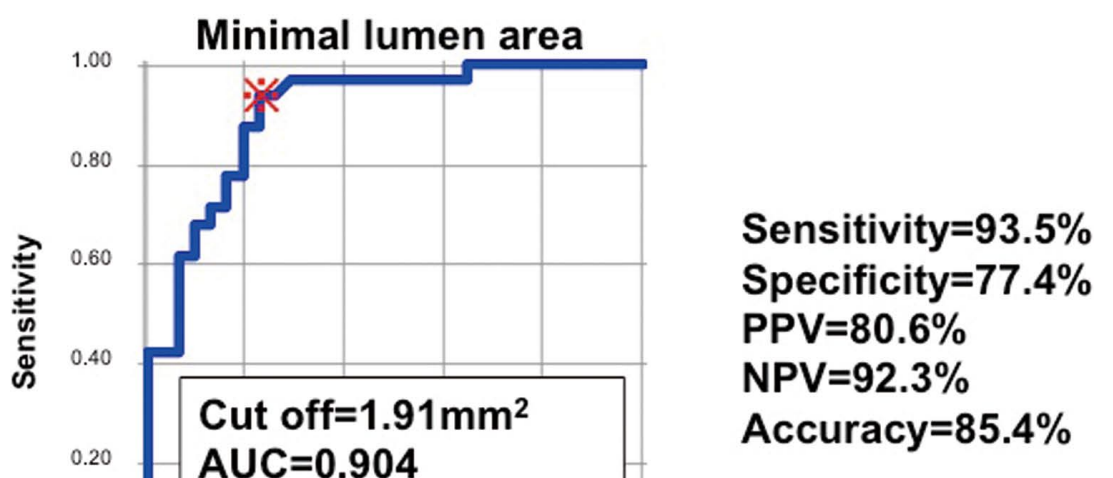

0.00

95\% Cl=0.829-0.978

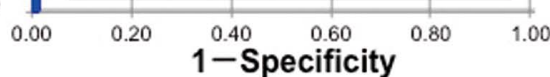

Minimal lumen diameter
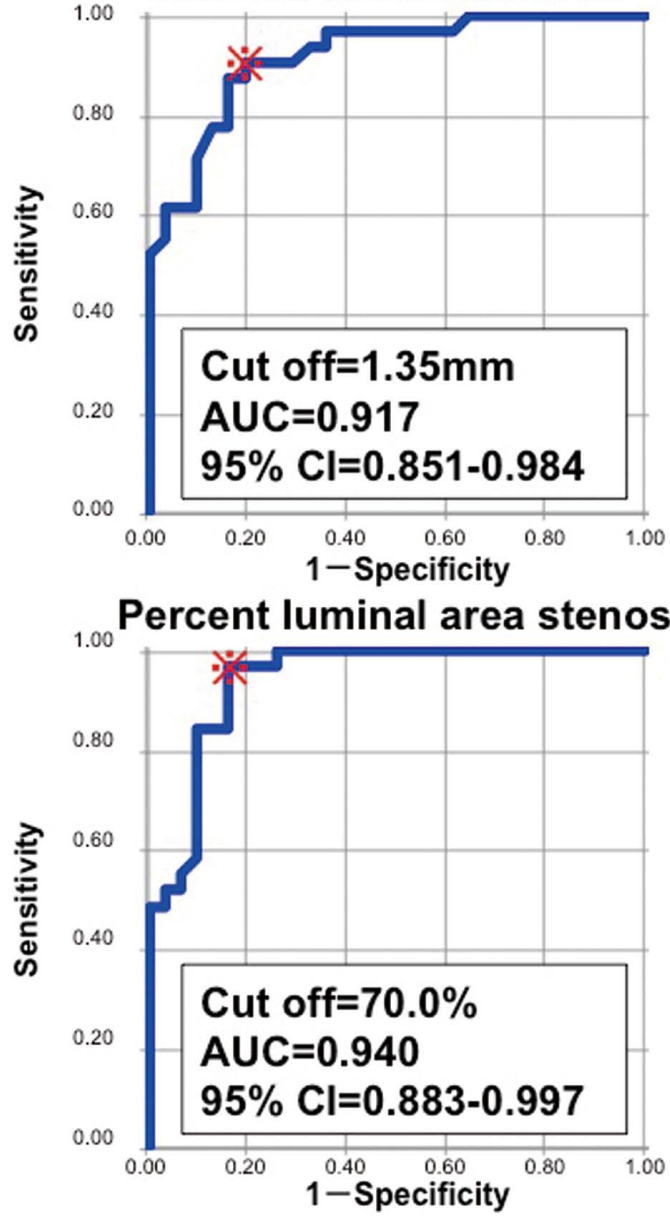

Figure 3. Cutoff values of OCT-derived MLA, MLD and percent luminal area stenosis for predicting FFR $<0.75$. Receiver-operating characteristic curve suggested an MLA $<1.91 \mathrm{~mm}^{2}$ (sensitivity: 93.5\%; specificity: $77.4 \%$; PPV: $80.6 \%$; NPV: 92.3\%; accuracy: $85.4 \%$ ), an MLD $<1.35 \mathrm{~mm}$ (sensitivity: $90.3 \%$; specificity: 80.6\%; PPV: 84.4\%; NPV: $84.6 \%$; accuracy: $85.5 \%$ ) and percent luminal area stenosis $>70.0 \%$ (sensitivity: 96.8\%; specificity: $83.9 \%$; PPV: 85.7\%; NPV: 96.3\%; accuracy: $90.3 \%$ ) as the best cutoff values for FFR $<0.75$. FFR, fractional flow reserve; MLA, minimal lumen area; MLD, minimal lumen diameter; OCT, optical coherence tomography; PPV, positive predictive value; NPV, negative predictive value. of ATP up to $180 \mu \mathrm{g} \cdot \mathrm{kg}^{-1} \cdot \mathrm{min}^{-1}$, but FFR values did not change from negative (FFR $\geq 0.75$ ) to positive $(<0.75)$ in any case. The overall median FFR was $0.72 \pm 0.14$ (range, 0.35-1.0). FFR $<0.75$ was observed in 31 lesions $(50.0 \%)$.

\section{FFR and QCA Measurement}

FFR correlated positively with MLD $(r=0.66, \mathrm{P}<0.01)$ and negatively with percent diameter stenosis $(\mathrm{r}=-0.67, \mathrm{P}<0.01)$.
FFR and OCT Measurement

FFR correlated significantly with OCT-measured MLA ( $\mathrm{r}=0.75$, $\mathrm{P}<0.01)$, MLD $(\mathrm{r}=0.76, \mathrm{P}<0.01)$ and percent luminal area stenosis $(\mathrm{r}=-0.77, \mathrm{P}<0.01)$ (Figure 2$)$. The best cutoff value of the OCT-measured MLA for predicting FFR $<0.75$ was $1.91 \mathrm{~mm}^{2}$ (sensitivity: $93.5 \%$; specificity: $77.4 \%$; positive predictive value (PPV): $80.6 \%$; negative predictive value (NPV): 92.3\%; accuracy: $85.4 \%$; area under the curve (AUC): 0.904; and $95 \%$ confidence interval (CI): 0.829-0.978). The best 
cutoff value of the OCT-measured MLD was $1.35 \mathrm{~mm}$ (sensitivity: 90.3\%; specificity: $80.6 \%$; PPV: $84.4 \%$; NPV: $84.6 \%$; accuracy: 85.5\%; AUC: 0.917; and 95\% CI: 0.851-0.984), and the best cutoff value of the OCT-measured percent luminal area stenosis was $70.0 \%$ (sensitivity: $96.8 \%$; specificity: 83.9\%; PPV: 85.7\%; NPV: 96.3\%; accuracy: 90.3\%; AUC: 0.940; and 95\% CI; 0.883-0.997) (Figure 3). The 23 vessels with MLA $>1.91 \mathrm{~mm}^{2}$ and percent luminal area stenosis $<70 \%$ all presented a negative value (ie, FFR $\geq 0.75$ ). In contrast, when the OCT-derived MLA and percent luminal area stenosis were both under those cutoff points, $28(90.3 \%)$ of 31 vessels demonstrated a positive FFR value $<0.75$ (Figure 4).

\section{Discussion}

The major findings of the present study are: (1) OCT-measured parameters showed a significant correlation with FFR values and (2) anatomically based OCT identified the best cutoff values for predicting FFR $<0.75$ were MLD $<1.35 \mathrm{~mm}$, MLA $<1.91 \mathrm{~mm}^{2}$ and percent luminal area stenosis $>70.0 \%$, all of which were associated with the functional severity of coronary stenosis. However, the best cutoff values of MLA and MLD measured by OCT in the present study were smaller than those reported in previous IVUS studies..$^{10,11}$

Several studies have reported a good correlation between FFR and IVUS-derived MLA for assessing coronary lesion severity. Since the late $1990 \mathrm{~s}$, an IVUS-derived MLA $<3.0 \mathrm{~mm}^{2}$ or $<4.0 \mathrm{~mm}^{2}$ has been suggested as a threshold for detecting functionally significant stenosis with FFR $<0.75 . .^{10,11}$ Therefore, we also defined coronary lesions with FFR $<0.75$ as functionally significant stenosis., ${ }^{4,15}$

In contrast, a recent study ${ }^{16}$ with a larger study population than previously demonstrated an IVUS-derived MLA $<2.4 \mathrm{~mm}^{2}$ as the best cutoff point for FFR $<0.80$, currently defined by consensus. ${ }^{9}$ This suggests that the cutoff value of MLA corresponding to FFR $<0.75$ is $<2.4 \mathrm{~mm}^{2}$, even with IVUS.

Moreover, the anatomic measurements of coronary lesions obtained using IVUS differ according to vessel size. Several studies investigating the IVUS parameters that correspond to functionally significant coronary stenosis have demonstrated different cutoff values of IVUS-derived MLA (range, 2.0$4.0 \mathrm{~mm}^{2}$ ) according to the reference lumen area (range, 5.5$11.9 \mathrm{~mm}^{2}$ ). On the other hand, the cutoff values of percent luminal stenosis were consistently $60-70 \% .^{10,11,16-21}$ The reference lumen area of $6.30 \mathrm{~mm}^{2}$ in the present study was relatively small, which might have led to the smaller OCT-derived MLA cutoff value of $1.91 \mathrm{~mm}^{2}$. However, the cutoff value of lumen area stenosis of $70 \%$ corresponded to previous IVUS reports.

Several studies have reported that coronary lumen dimensions measured by OCT are smaller than those measured by IVUS. ${ }^{22,23}$ Yamaguchi et al evaluated the in vivo differences between IVUS and OCT for human coronary lumen dimensions and found that MLA was significantly smaller when measured by OCT with occlusion technique than when measured by IVUS (mean difference, $0.4 \mathrm{~mm}^{2}$ ).22 Gonzalo et al also reported the lumen area measured by OCT with and without occlusion as much smaller than that measured by IVUS (mean difference of $1.67 \mathrm{~mm}^{2}$ with occlusion technique and $1.11 \mathrm{~mm}^{2}$ with non-occlusion technique). ${ }^{23}$ Several explanations of this phenomenon are proposed. The IVUS catheter may stretch small arteries (Dotter effect), because of its large size (3Fr $[1.0 \mathrm{~mm}])$ compared with an OCT image wire $(0.016$ inches $[0.41 \mathrm{~mm}])$, producing an artificially larger vessel size. Intra-

\begin{tabular}{|c|c|c|}
\hline \multirow[b]{3}{*}{ है $<1.91$} & \multicolumn{2}{|c|}{ Percent luminal area stenosis, \% } \\
\hline & $>70$ & $\leq 70$ \\
\hline & $\begin{array}{l}\text { FFR }<0.75: 28 \\
\text { FFR } \geq 0.75: 3\end{array}$ & $\begin{array}{l}\text { FFR }<0.75: 1 \\
\text { FFR } \geq 0.75: 4\end{array}$ \\
\hline$\sum_{\geq 1.91}$ & $\begin{array}{l}F F R<0.75: 2 \\
F F R \geq 0.75: 0\end{array}$ & $\begin{array}{l}F F R<0.75: 0 \\
F F R \geq 0.75: 23\end{array}$ \\
\hline $\begin{array}{l}\text { Figure } 4 . \\
\text { bining both } \\
\text { area stenos } \\
\text { or absence } \\
\text { OCT, optica }\end{array}$ & $\begin{array}{l}\text { mbination of OCT } \\
\text { riteria of OCT-deri } \\
\text { showed a high po } \\
\text { f functionally signifi } \\
\text { coherence tomogr }\end{array}$ & $\begin{array}{l}\text { d cutoff values. Com } \\
\text { A and percent lumina } \\
\text { o predict the presenc } \\
\text { ronary artery stenosis }\end{array}$ \\
\hline
\end{tabular}

coronary perfusion pressure may be reduced during balloon inflation followed by continuous injection at a rate of $0.5 \mathrm{ml} / \mathrm{s}$ to eliminate red blood cells, and the pressure reduction may generate smaller artificial vessel dimensions during OCT image acquisition. The greater resolution of OCT enables optimal definition of the lumen-plaque border compared with IVUS imaging. Finally, slight z-offset drift during OCT image acquisition may lead to misreading measurement of vessel dimensions. Therefore, the cutoff value of OCT-derived MLA, especially when performed with the occlusion technique, for predicting functionally significant stenosis should be smaller than IVUS-derived MLA. The cutoff value of an OCT-derived MLA of $<1.91 \mathrm{~mm}^{2}$ for functionally significant stenosis is feasible. Moreover, the effect of the MLA on functional significance should differ according to the reference vessel size for each lesion. We need to take into consideration not only MLA but also percent luminal area stenosis. The combination of MLA and percent luminal area stenosis criteria could provide more accurate assessment of significant coronary stenosis.

Finally, we have to keep in mind that even IVUS for assessment of non-left main coronary arteries with intermediate coronary stenosis is classified as class IIb in the current ACC/ AHA/SCAI PCI guidelines. ${ }^{24}$ And the appropriate role of OCT on this issue has not been established yet. Anatomical parameters do not always predict functional significance, because the functional severity of a coronary lesion depends on not only the anatomical severity itself of the epicardial coronary lesion but also many other factors such as the lesion's location, the perfusion territory of each coronary vessel in where the target lesion exists, and so on. Our results also demonstrated that any OCT-derived cut off values had only moderate PPV. On the other hand, the NPVs of the OCT parameters were notably high. These results are consistent with a recent IVUS study. ${ }^{16}$ Intravascular imaging modalities, including IVUS and OCT, might have a higher potential for excluding the absence of ischemia rather than predicting the presence of ischemia.

\section{Study Limitations}

First, this was a retrospective study with a small sample population. Second, factors of epicardial coronary stenosis that disturb coronary flow are not only lesion dimension, but also lesion length. However, we used only dimensional parameters when analyzing the relationship between FFR and OCT measurement to simplify the evaluation of coronary stenosis. Fur- 
thermore, lesion dimension influences coronary resistance more notably than does lesion length, because epicardial coronary resistance increases linearly according to lesion length and exponentially according to the extent of narrowing, based on Poiseuille's law.

Third, the cutoff values of OCT-derived coronary lesion parameters for predicting functionally significant stenosis may vary with the location of the coronary stenosis. In other words, the cutoff value of OCT-derived coronary lesion parameters might be affected by the reference vessel's size. For example, a proximal LAD lesion, which has a larger perfusion territory than other lesions, should provide the lowest FFR value if the severity of epicardial coronary stenosis is the same. However, because of the small numbers, we could not identify differences in cutoff values between lesions.

Fourthly, factors that cause deterioration of the microvasculature, such as diabetes mellitus and left ventricular hypertrophy, may affect the FFR value. ${ }^{25-28}$ In addition, accurate measurement of FFR depends on achieving maximal hyperemia in the myocardial territory subtended by the stenosis. Therefore, we tried to obtain maximal hyperemia in all cases by administering adequate amounts of ATP $\left(150-180 \mu \mathrm{g} \cdot \mathrm{kg}^{-1}\right.$. $\left.\min ^{-1}\right){ }^{29}$

Finally, we performed all OCT procedures by TD-OCT using the conventional occlusion technique. There are some limitations with regard to the complex procedure of TD-OCT, as well as technical matters, in a clinical setting. The influence of pressure reduction by balloon occlusion might differ according to lesion morphology, such as severely calcified lesions. The patient's condition during OCT image acquisition using occlusion balloon is quite different from the physiological state during FFR measurement. Therefore, it would be difficult to use the cutoff value of this study under other situations. Furthermore, the TD-OCT image wire is often positioned eccentrically, especially in curved vessel segments, even though centering of the image wire over the entire length of the target segments is very important for obtaining more reliable cross-sectional images. This eccentric position of the image wire may have affected the quantitative analysis by TD-OCT. ${ }^{30}$

Frequency-domain OCT (FD-OCT) has been developed to overcome many of the technical limitations of the current TDOCT system, including higher frame rates (100 frame/s), a wider scan diameter $(10 \mathrm{~mm})$, and a faster image acquisition rate $(20 \mathrm{~mm} / \mathrm{s})$ without the loss of image quality. It can be delivered as a rapid exchange catheter over a conventional coronary guidewire. ${ }^{12}$ Furthermore, FD-OCT may be able to provide better measurement of vessel dimensions than TDOCT because its image acquisition method does not require proximal balloon occlusion..$^{13,23,31}$ Hence, further investigations exploring the relationship between coronary dimensions assessed by FD-OCT and FFR are warranted. Our study had similar findings regarding the cutoff of percent lumen area stenosis to those of previous IVUS studies, which guarantees the accuracy of our results.

\section{Conclusions}

Anatomical severity of coronary artery stenosis assessed by TD-OCT correlates significantly with FFR values. Moreover, OCT-derived anatomical parameters have the potential to predict functionally significant stenosis with a FFR $<0.75$, although the present values were smaller than those previously reported in IVUS studies.

\section{Disclosures}

Funding Sources: None. No authors have any financial interest, arrangement, or affiliation with any organization that could be perceived as a real or apparent conflict of interest in the context of this article.

\section{References}

1. Beller GA, Zaret BL. Contributions of nuclear cardiology to diagnosis and prognosis of patients with coronary artery disease. Circulation 2000; 101: $1465-1478$.

2. Nakamura M. Angiography is the gold standard and objective evidence of myocardial ischemia is mandatory if lesion severity is questionable: Indication of PCI for angiographically significant coronary artery stenosis without objective evidence of myocardial ischemia (Pro). Circ J 2011; 75: 204-210.

3. Lin GA, Dudley RA, Lucas FL, Malenka DJ, Vittinghoff E, Redberg RF. Frequency of stress testing to document ischemia prior to elective percutaneous coronary intervention. JAMA 2008; 300: $1765-$ 1773 .

4. Pijls NH, De Bruyne B, Peels K, Van Der Vort PH, Bonnier HJ, Bartunek J, et al. Measurement of fractional flow reserve to assess the functional severity of coronary- artery stenoses. $N$ Engl J Med 1996; 334: $1703-1708$.

5. Shaw LJ, Berman DS, Maron DJ, Mancini GB, Hayes SW, Hartigan PM, et al. Optimal medical therapy with or without percutaneous coronary intervention to reduce ischemic burden: Results from the Clinical Outcomes Utilizing Revascularization and Aggressive Drug Evaluation (COURAGE) trial nuclear substudy. Circulation 2008; 117: $1283-1291$.

6. Akasaka T. What can we expect in PCI in patients with chronic coronary artery disease. Indication of PCI for angiographically significant coronary artery stenosis without objective evidence of myocardial ischemia (Con). Circ J 2011; 75: 211-217.

7. Berger A, Botman KJ, MacCarthy PA, Wijns W, Bartunek J, Heyndrickx GR, et al. Long-term clinical outcome after fractional flow reserve-guided percutaneous coronary intervention in patients with multivessel disease. J Am Coll Cardiol 2005; 46: 438-442.

8. Wongpraparut N, Yalamanchili V, Pasnoori V, Satran A, Chandra M, Masden R, et al. Thirty-month outcome after fractional flow reserveguided versus conventional multivessel percutaneous coronary intervention. Am J Cardiol 2005; 96: 877-884.

9. Tonino PA, De Bruyne B, Pijls NH, Siebert U, Ikeno F, van't Veer M, et al. FAME Study Investigators. Fractional flow reserve versus angiography for guiding percutaneous coronary intervention. $N$ Engl J Med 2009; 360: $213-224$

10. Takagi A, Tsurumi Y, Ishii Y, Suzuki K, Kawana M, Kasanuki H. Clinical potential of intravascular ultrasound for physiological assessment of coronary stenosis: Relationship between quantitative ultrasound tomography and pressure-derived fractional flow reserve. Circulation 1999; 100: 250-255.

11. Briguori C, Anzuini A, Airoldi F, Gimelli G, Nishida T, Adamian M, et al. Intravascular ultrasound criteria for the assessment of the functional significance of intermediate coronary artery stenoses and comparison with fractional flow reserve. Am J Cardiol 2001; 87: 136141.

12. Takarada S, Imanishi T, Liu Y, Ikejima H, Tsujioka H, Kuroi A, et al. Advantage of next-generation frequency-domain optical coherence tomography compared with conventional time-domain system in the assessment of coronary lesion. Catheter Cardiovasc Interv 2010; 75: 202-206.

13. Kataiwa H, Tanaka A, Kitabata H, Matsumoto H, Kashiwagi M, Kuroi $\mathrm{A}$, et al. Head to head comparison between the conventional balloon occlusion method and the non-occlusion method for optical coherence tomography. Int J Cardiol 2011; 146: 186-190.

14. Tanaka A, Imanishi T, Kitabata H, Kubo T, Takarada S, Tanimoto T, et al. Lipid-rich plaque and myocardial perfusion after successful stenting in patients with non-ST-segment elevation acute coronary syndrome: An optical coherence tomography study. Eur Heart J 2009; 30: $1348-1355$.

15. Pijls NH, van Schaardenburgh P, Manoharan G, Boersma E, Bech JW, van't Veer M, et al. Percutaneous coronary intervention of functionally nonsignificant stenosis: 5-year follow-up of the DEFER Study. J Am Coll Cardiol 2007; 49: 2105-2111.

16. Kang SJ, Lee JY, Ahn JM, Mintz GS, Kim WJ, Park DW, et al. Validation of intravascular ultrasound-derived parameters with fractional flow reserve for assessment of coronary stenosis severity. Circ Cardiovasc Interv 2011; 4: 65-71.

17. Koo BK, Yang HM, Doh JH, Choe H, Lee SY, Yoon CH, et al. Optimal intravascular ultrasound criteria and their accuracy for de- 
fining the functional significance of intermediate coronary stenoses of different locations. J Am Coll Cardiol Interv 2011; 4: 803-811.

18. Ben-Dor I, Torquson R, Gaglia MA Jr, Gonzalez MA, Maluenda G, Bui $\mathrm{AB}$, et al. Correlation between fractional flow reserve and intravascular ultrasound lumen area in intermediate coronary artery stenosis. Eurointervention 2011; 7: 225-233.

19. Ahn JM, Kang SJ, Mintz GS, Oh JH, Kim WJ, Lee JY, et al. Validation of minimal luminal area measured by intravascular ultrasound for assessment of functionally significant coronary stenosis comparison with myocardial perfusion imaging. J Am Coll Cardiol Interv 2011; 4: 665-671.

20. Lee CH, Tai BC, Soon CY, Low AF, Poh KK, Yeo TC, et al. New set of intravascular ultrasound-derived anatomic criteria for defining functionally significant stenoses in small coronary arteries (results from Intravascular Ultrasound Diagnostic Evaluation of Atherosclerosis in Singapore [IDEAS] study). Am J Cardiol 2010; 105: $1378-$ 1384.

21. Nishioka T, Amanullah AM, Luo H, Berglund H, Kim CJ, Nagai T, et al. Clinical validation of intravascular ultrasound imaging for assessment of coronary stenosis severity: Comparison with stress myocardial perfusion imaging. J Am Coll Cardiol 1999; 33: 1870-1878.

22. Yamaguchi T, Terashima M, Akasaka T, Hayashi T, Mizuno K, Muramatsu T, et al. Safety and feasibility of an intravascular optical coherence tomography image wire system in the clinical setting. Am J Cardiol 2008; 101: 562-567.

23. Gonzalo N, Serruys PW, Garcia-Garcia HM, van Soest G, Okamura T, Ligthart J, et al. Quantitative ex vivo and in vivo comparison of lumen dimensions measured by optical coherence tomography and intravascular ultrasound in human coronary arteries. Rev Esp Cardiol 2009; 62: 615-624.

24. Levine GN, Bates ER, Blankenship JC, Bailey SR, Bittl JA, Cercek B, et al. 2011 ACCF/AHA/SCAI Guideline for Percutaneous Coronary Intervention: A Report of the American College of Cardiology Foundation/American Heart Association Task Force on Practice Guidelines and the Society for Cardiovascular Angiography and Interventions. Circulation 2011; 124: e574-e651.

25. Meuwissen M, Chamuleau SA, Siebes M, Schotborgh CE, Koch KT, de Winter RJ, et al. Role of variability in microvascular resistance on fractional flow reserve and coronary blood flow velocity reserve in intermediate coronary lesions. Circulation 2001; 103: 184-187.

26. Nahser PJ Jr, Brown RE, Oskarsson H, Winniford MD, Rossen JD. Maximal coronary flow reserve and metabolic coronary vasodilation in patients with diabetes mellitus. Circulation 1995; 91: 635-640.

27. Di Carli MF, Janisse J, Grunberger G, Ager J. Role of chronic hyperglycemia in the pathogenesis of coronary microvascular dysfunction in diabetes. J Am Coll Cardiol 2003; 41: 1387-1393.

28. Krams R, Kofflard MJ, Duncker DJ, Von Birgelen C, Carlier S, Kliffen M, et al. Decreased coronary flow reserve in hypertrophic cardiomyopathy is related to remodeling of the coronary microcirculation. Circulation 1998; 97: 230-233.

29. McGeoch RJ, Oldroyd KG. Pharmacological options for inducing maximal hyperaemia during studies of coronary physiology. Catheter Cardiovasc Interv 2008; 71: 198-204.

30. Sawada T, Shite J, Negi N, Shinke T, Tanino Y, Ogasawara D, et al. Factors that influence measurements and accurate evaluation of stent apposition by optical coherence tomography: Assessment using a phantom model. Circ J 2009; 73: 1841-1847.

31. Ozaki Y, Kitabata H, Tsujioka H, Hosokawa S, Kashiwagi M, Ishibashi $\mathrm{K}$, et al. Comparison of contrast media and low-molecular-weight dextran for frequency-domain optical coherence tomography. Circ J 2012; 76: $922-927$. 